\title{
Несформировавшиеся кишечные свищи, расположенные на эвентрированных петлях. Нестандартные ситуации - стандартные решения
}

\author{
H. I. ANDRIEYEV, V. K. LOHACHEV \\ SI "Institute of General and Emergency Surgery of NAMS of Ukraine", Kharkiv
}

\section{NON-FORMED INTESTINAL FISTULAS, LOCATED ON EVENTRANED LOOPS. NON-STANDARD SITUATIONS - STANDARDSOLVING}

\begin{abstract}
Изучены результаты обтурации у 109 пациентов. Определены 6 типов топографо-анатомических отношений петли, несущей свищ к ране. Установлено, что у 47,8 \% пациентов обтураторы линейного типа не обеспечивают герметизацю свищей. Применение в этих случаях конструкций с элементом, моделируемым по кривизне, позволяет повысить эффективность метода в 1,6 раза.

The results of obturation are studied in 109 patients. 6 types of topografo-anatomical relation of loop, bearing fistulae to the wound are determined. It is set that in $47,8 \%$ of patients the occluders of linear type do not provide pressurizing of fistulas. Application in these cases of constructions with an element, designed on curvature allows to promote efficiency of method in 1,6 time.
\end{abstract}

Постановка проблемы и анализ последних исследований и публикаций. Основные сложности в выборе метода лечения возникают при несформировавшихся наружных свищах тонкой кишки (ННСТК) - острой фазе, на фоне или вследствие незавершенного гнойно-воспалительного процесса в ране и/или брюшной полости, что, по мнению многих авторов, является противопоказанием к оперативному лечению, а также применению обтурации $[1,2,3]$.

Исходя из опыта прошлых лет, необходимо отметить, что лечение ННСТК в том периоде не имело четкого алгоритма как в области инфузионной терапии, так и в области хирургического пособия.

Цель работы: изучить результаты обтурации ННСТК в зависимости от типа расположения свищенесущей петли и применяемых конструкций.

Материалы и методы. Изучены результаты лечения 109 пациентов с неформировавшимися свищами, расположенными на эвентрированных петлях тонкой кишки. У всех пациентов изучались морфометрические параметры дефекта кишечной стенки, приводящего и отводящего отдела кишки с по- мощью специального циркуля-измерителя или при мануальном (пальцевом) исследовании. Изучались размеры свищевого дефекта, отношение свищенесущей петли к ране и угол между приводящим и отводящим отделом кишки, несущей свищ.

Результаты исследований и их обсуждение. При изучении отношения свищенесущей петли были выявлены следующие типы (рис. 1).

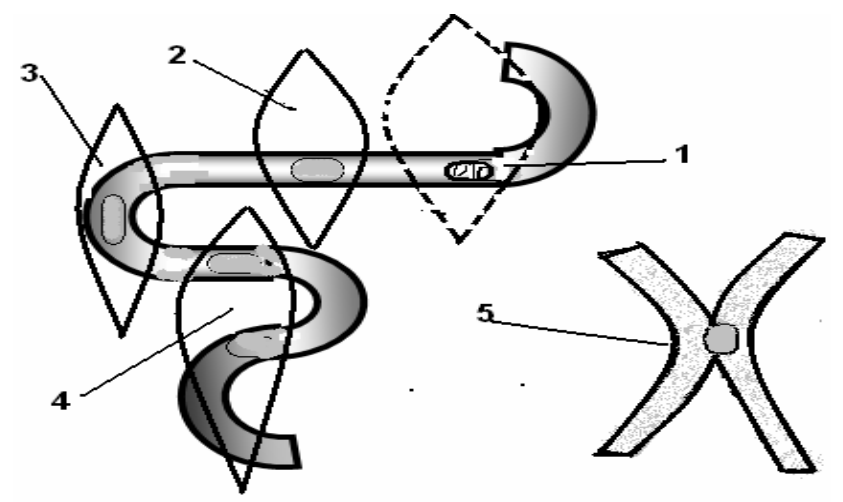

Рис. 1. Типы свищей в зависимости от топографо-анатомических отношений в горизонтальной плоскости: 1 - горизонтальный Г-образный; 2 - линейный тип; 3 - U-образный горизонтальный; 4 -S-образный; 5 -Х-образный. 
В поперечной плоскости встречались аркообразный, вертикальный Г-образный и U-образный типы (рис. 2).

Разработанные ранее конструкции обтураторов в основном были предназначены для временной герметизации свищевых дефектов, не превышавших в поперечном направлении $1 / 2$ диаметра кишки, либо дефектов любого размера при линейном типе отношения свищенесущей петли к ране. Кроме того, для внутрикишечных элементов применялась трубка из силиконизированной резины диаметром 20-25 мм, которая обладала достаточной эластичностью, что позволяло использовать ее без доработок для герметизации свищей, расположенных на петлях со значительным изгибом в зоне дефекта.

С начала 90-х годов прошлого века трубки из силиконизированной резины диаметром более 12 мм перестали выпускаться серийно, и внутрикишечные элементы обтураторов стали изготавливаться из поливинилхлоридной (ПВХ) трубки. Сразу же возникли проблемы с временной герметизацией свищей, расположенных на петлях, имеющих изгиб. Более жесткий материал не обеспечивал конгруэнтность по оси кишки в зоне дефекта. Это привело к изменению эффективности применения разработанных конструкций (табл. 1).

Как видно из таблицы 1 , применение конструкций обтураторов разработки 50-70-х годов обеспечивало эффективную герметизацию дефектов в $1 / 5-1 / 6$ случаев при линейном и горизонтальном
U-образном типе свищей, большей частью при дефектах, не превышавших 1/2 диаметра кишки. Усовершенствованные конструкции, разработанные в 80-90-х годах, позволяли эффективно обеспечить герметизм при линейном и X-образном типе. В последнем случае обтурация осуществлялась по принципу bypass, аналогично линейному типу. При остальных типах эффективность не превышала $50 \%$ (9 из 18 наблюдений), и только в том случае, когда в зоне свищевого дефекта имелся линейный участок кишки протяженностью $\mathrm{L}+30$ мм, где $\mathrm{L}-$ линейный размер свищевого дефекта. В остальных случаях обтурация либо вообще не выполнялась, либо была неэффективной.

Это побудило к разработке обтураторов с внутрикишечным элементом, моделируемым по кривизне и технологии предварительного стендового макетирования свища. Суть последнего заключается в изучении топографо-анатомических отношений свищенесущей петли к ране, моделировании аналогичных условий на специальном стенде, изготовлении соответствующей конструкции, апробации ее на стенде и после этого установки в свищ.

В результате применения такой технологии эффективность метода была повышена (табл. 2).

Судя по приведенным в таблице 2 данным, эффективность метода повысилась с 76,7 до 89,3\%, при этом эффективность обтурации при свищах нелинейного типа повысилась с 50 до $81,25 \%$.

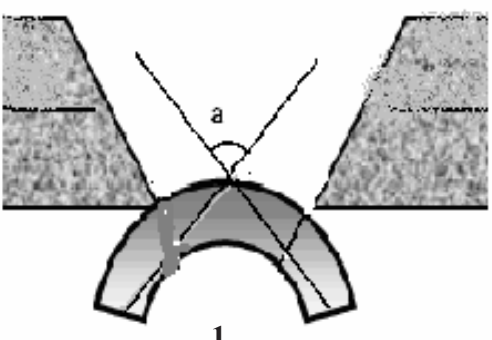

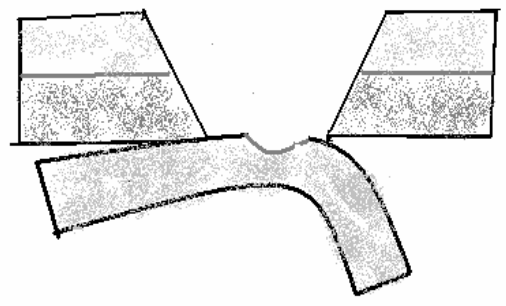

2

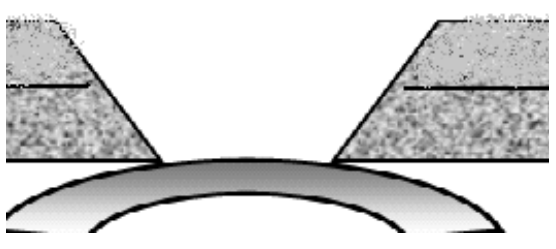

3

Рис. 2. Варианты расположения эвентрированной петли по отношению к париетальной брюшине и ране: $1-$ вертикальный U-образный; 2 - вертикальный Г-образный; 3 - дугообразный.

Таблица 1. Результаты обтурации кишечных свищей, расположенных на эвентрированных петлях в зависимости от периода работы

\begin{tabular}{||l|c|c|c|c||}
\hline \multirow{2}{*}{\multicolumn{1}{|c|}{ Типы свищей }} & \multicolumn{2}{c|}{ 1-й период } & \multicolumn{2}{c||}{ 2-й период } \\
\cline { 2 - 5 } & всего & обтур. & всего & 22 \\
\hline Линейный тип & 24 & 4 & 22 & 1 \\
\hline Г-образный горизонтальный & 2 & 0 & 3 & 4 \\
\hline U-образный горизонтальный & 5 & 1 & 6 & 1 \\
\hline S-образный & 1 & 0 & 2 & 3 \\
\hline Х-образный & 0 & 0 & 4 & 2 \\
\hline U-образный вертикальный & 4 & 0 & 3 & 3 \\
\hline Г-образный вертикальный & 2 & 0 & 43 & $33(76,7 \%)$ \\
\hline Всего & 38 & $5(13,2 \%)$ & \multicolumn{3}{|c||}{} \\
\hline
\end{tabular}


Таблица 2. Результаты применения технологии обтурации несформировавшихся свищей тонкой кишки на эвентрированных петлях

\begin{tabular}{||l|c|c|c|c||}
\hline \multirow{2}{*}{\multicolumn{1}{|c|}{ Типы свищей }} & \multicolumn{2}{c|}{ 2-й период } & \multicolumn{2}{c||}{ 3-й период } \\
\cline { 2 - 5 } & всего & эффективно & всего & эффективно \\
\hline Линейный тип & 22 & 22 & 10 & 2 \\
\hline Г-образный горизонтальный & 3 & 1 & 2 & 5 \\
\hline U-образный горизонтальный & 6 & 4 & 6 & 1 \\
\hline S-образный & 2 & 1 & 2 & 2 \\
\hline Х-образный & 3 & 3 & 2 & 3 \\
\hline U-образный вертикальный & 4 & 2 & 4 & 2 \\
\hline Г-образный вертикальный & 3 & 1 & 2 & $25(89,3 \%)$ \\
\hline Всего & 43 & $33(76,7 \%)$ & 28 & 2 \\
\hline
\end{tabular}

Выводы. 1. У 47,8 \% пациентов с несформировавшимися свищами тонкой кишки, расположенными на эвентрированных петлях, отсутствуют условия для применения линейных конструкций обтураторов.

\section{СПИСОК ЛИТЕРАТУРЫ}

1. Атаманов В. В. Клинико-морфологические параллели у больных с несформированными кишечными свищами / В. В. Атаманов // Физиология и патология органов пищеварения. Новосибирск, 1986. - С. 33-38.

2. Богданов А. В. Свищи пищеварительного тракта в практи-
2. Применение предварительного стендового макетирования и конструкций обтураторов с внутрикишечным элементом, моделируемым по кривизне, позволяет повысить эффективность метода в 1,6 раза.

ке общего хирурга / А. В. Богданов. - М. : Издатель Мокеев, 2001. $-200 \mathrm{c}$.

3. Белоконев В. И. Диагностика и лечение свищей желудочнокишечного тракта / В. И. Белоконев, Е. П. Измайлов. - Самара : ГП "Перспектива", 2005. - 239 с. 